\section{Outcome of Patients Treated With Noninvasive Ventilation by a Medical Emergency Team on the Wards: Is It Really Scarce Monitoring?}

\section{To the Editor:}

I have read with attention the original article entitled "Outcome of patients treated with noninvasive ventilation by a medical emergency team on the wards." 1 In this study, the authors prospectively evaluated 238 patients with an $\mathrm{S}_{\mathrm{pO}_{2}}$ of $<90 \%$ and a breathing frequency of $>28$ breaths/min identified by a medical emergency team (MET). Fifty-four of these patients received noninvasive ventilation (NIV), whereas another 75 patients did not; both groups were evaluated in the general medicine ward.

The authors found significant differences in intubation percentage, with the rate being higher in the group without NIV. No significant differences in the percentage of mortality in the ICU and in the mortality assessed at 28 days in both groups were found. The authors concluded that NIV in a select group of patients with exacerbation of COPD/asthma and acute lung edema could be maintained regularly in the ward with no additional staffing and monitoring in the context of the assessment of an MET.

I have some remarks on this study.

1. Of the 238 patients initially evaluated, $45 \%$ were excluded, and $83(34 \%)$ were transferred to the ICU. Data on the causes of transfer to the ICU, use of NIV, intubation, mortality in this group, and how many of these patients corresponded to exacerbations of COPD/asthma or acute lung edema were not provided.

2. The authors suggested maintaining and monitoring NIV in the general ward. However, noninvasive ventilators with sophisticated software monitoring (BiPAP Vision, Philips Respironics, Murrysville, Pennsylvania), which included exhaled tidal volume, minute volume, leak check, breathing frequency, $\mathrm{T}_{\mathrm{I}} / \mathrm{T}_{\text {tot }}$, peak inspiratory pressure, $\mathrm{F}_{\mathrm{IO}_{2}}$, and even average volume-assured pressure support $^{2}$ or pressure controlled ventilation with backup modes of ventilation in patients who did not tolerate initially or did not respond to CPAP or bi-level positive airway pressure were used. Furthermore, the MET consisted of an internal medicine physician, a critical care nurse, a respiratory therapist, and a standby pharmacist for prompt delivery of medication. The Scientific Group on Respiratory Intensive Care of the Italian Association of Hospital Pneumologists and the European Respiratory Society clearly distinguish between respiratory care units with a nurse/patient ratio of $1: 5$ or $1: 6$ in common rooms..$^{3,4}$

3. The duration of the evaluation period of the MET was $82-118 \mathrm{~h}(P=.001)$, which was in favor of the NIV group, indicating that the time spent in the general ward on these patients is the same as that spent in respiratory care units or ICUs. Moreover, the authors reported $\mathrm{pH}$ values of $7.27 \pm 0.15$ in the NIV group. Evidence exists of the feasibility of using NIV for patients with mild-to-moderate COPD exacerbations but with $\mathrm{pH}$ values $>7.30 .5,6$

I believe that, with early identification, there is a select group of patients who may benefit from the use of NIV outside the ICU, but they must be evaluated with predictors of success 7,8 and must also be willing to undergo NIV outside the ICU when there is a limited availability of beds in the ICU/ respiratory care unit.

Killen H Briones Claudett MD

Department of Respiratory Medicine Panamericana Clinic

Department of Respiratory MedicineIntensive Care Santa Maria Clinic Pulmonology Department Military Hospital Guayaquil, Ecuador

The author has disclosed no conflicts of interest.

DOI: $10.4187 /$ respcare. 03265

\section{REFERENCES}

1. Khalid I, Sherbini N, Qushmaq I, Qabajah MR, Nisar A, Khalid TJ. Outcome of patients treated with noninvasive ventilation by a medical emergency team on the wards. Respir Care 2014;59(2):186-192.

2. Briones Claudett KH, Briones Claudett M, Chung Sang Wong M, Nuques Martinez A, Soto Espinoza R, Montalvo M, et al. Noninvasive mechanical ventilation with average volume assured pressure support (AVAPS) in patients with chronic obstructive pulmonary disease and hypercapnic en- cephalopathy. BMC Pulm Med 2013;13: 12.

3. Corrado A, Roussos C, Ambrosino N, Confalonieri M, Cuvelier A, Elliott M, et al. European Respiratory Society Task Force on epidemiology of respiratory intermediate care in Europe. Respiratory intermediate care units: a European survey. Eur Respir J 2002;20(5):1343-1350.

4. Scala R, Corrado A, Confalonieri M, Marchese S, Ambrosino N, Scientific Group on Respiratory Intensive Care of the Italian Association of Hospital Pneumologists. Increased number and expertise of Italian respiratory high-dependency care units: the second national survey. Respir Care 2011; 56(8):1100-1117.

5. Fiorino S, Detotto E, Battilana M, BacchiReggiani L, Moretti R, Benfenati F, et al. Severe exacerbations of chronic obstructive pulmonary disease: management with noninvasive ventilation on a general medicine ward. Ital J Med 2010;4(3):173-178.

6. Plant PK, Owen JL, Elliott MW. Early use of non-invasive ventilation for acute exacerbations of chronic obstructive pulmonary disease on general respiratory wards: a multicentre randomized controlled trial. Lancet 2000;355(9219):1931-1935.

7. Briones Claudett $\mathrm{KH}$, Briones Claudett $\mathrm{MH}$, Chung Sang Wong MA, Andrade MG, Cruz Pico CX, Esquinas A, Diaz GG. Noninvasive mechanical ventilation in patients with chronic obstructive pulmonary disease and severe hypercapnic neurological deterioration in the emergency room. Eur J Emerg Med 2008;15(3):127-133.

8. Passarini JN, Zambon L, Morcillo AM, Kosour C, Saad IA. Use of non-invasive ventilation in acute pulmonary edema and chronic obstructive pulmonary disease exacerbation in emergency medicine: predictors of failure. Rev Bras Ter Intensiva 2012; 24(3):278-283.

\section{Outcome of Patients Treated With Noninvasive Ventilation by a Medical Emergency Team on the Wards: Scarce and Probably Secure and Resourceful Monitoring in Select Subjects- Reply}

\section{In Reply:}

We reviewed the comments by Killen $\mathrm{H}$ Briones Claudett. Of 238 subjects, we excluded the ones who were immediately transferred to the ICU. These subjects were deemed to be ICU candidates during the initial medical emergency team (MET) evaluation and were not the focus of our study. 